\title{
Affects, Attunements and the Intersubjective Self: Perspectives from Early Development
}

\author{
Stephen Seligman*
}

ABSTRACT. - This paper conceptualizes the self and related concepts so as to emphasize interrelatedness rather than autonomy. From this view of a subject embedded in relationships as a point of departure, it then critiques and restates certain analyticallyoriented concepts so as to render them in a more fully intersubjective frame: "affect attunement" (Stern, 1985), "mirroring" (Kohut, 1977), empathy, and projective identification. This approach draws on drawing on the infant observation research that has emerged in recent decades.

Keywords: Self, affect attunement, intersubjectivity, empathy, projective identification, mirroring.

'Two-person psychoanalysis' has been quite influential throughout psychoanalysis over the last decades. Still, many current conceptualizations about subjectivity and intersubjectivity have not fully incorporated the implications of this new perspective. This paper begins with a critique of conceptualizations of the self that emphasize autonomy at the expense of interrelatedness. With this view of a subject embedded in relationships as a point of departure, it then considers the concepts of "affect attunement" (Stern, 1985), "mirroring" (Kohut, 1977), empathy and projective identification. I propose that some readings of such concepts have been constrained by the limitations of more or less reified images of a static self. This bias appears in Ego Psychology, contemporary Kleinian analysis, and the Kohut's original Self Psychology, despite their creativity and generativity.

\footnotetext{
*Clinical Professor of Psychiatry, University of California, San Francisco; Joint Editorin-Chief, Psychoanalytic Dialogues; Training and Supervising Analyst, San Francisco Center for Psychoanalysis \& Psychoanalytic Institute of Northern California, USA.

E-mail: stephen.seligman331@gmail.com
} 
Instead, these concepts can be rendered in the most dynamic and useful ways when approached from a fully intersubjective perspective. From this point of view, the most fundamental forms of personal, cultural and political-economic organization and meaning are created, negotiated and renegotiated in ongoing, dynamic, relatively contingent processes of mutual regulation, mutual influence and mutual representation. In other words, knowledge and identities are constructed in networks of relationships. In psychoanalysis, development, and in everyday life, experiences of self and others are continually and fundamentally influenced in the ongoing fluxes of these fields. Subjectivity is more a matter of 'self-with-other' than of 'self-in-itself.'

This is not to say that is no such thing as a self. Continuity, identity and differentiation are core aspects of subjectivity, and there are always constraints from personal history, endowment or biology. But considerations of self-experience should refer-in their most fundamental structure - to the social and cultural processes within which they are embedded. Many contemporary analysts have been drawn to nonlinear dynamic systems theories in working toward integrative models in this domain. (Coburn, 2002; Galatzer-Levy, 2002; Sander, 2002; Seligman, 2005; Stolorow, 1997)

\section{Intersubjective Infancy Research and the Intersubjective self}

This perspective closely resonates with the intersubjectively-oriented infancy research that emerged from many different fields in the 1970's and since. (See Seligman, 2018, for a summary of these developments and their implications for psychoanalysis.) There, the focus is parent-infant relationships, with their dynamic flux and flow of mutual influence and regulation, shared meanings and affective states, all intertwined with individual bodies and emotions. With regard to both development and analytic practice, this general orientation has been featured in Relational Psychoanalysis and Intersubjective Systems Theory: The dyad is the basic unit in these orientations. They have much in common with Winnicott's (1960) "theory of the parent-infant relationship"- that "there is no infant" without the mother. My approach here reflects my own experience as a psychoanalyst involved with both infant development research and clinical work with infants and their parents. Infant observation research has provided a context for me to work out certain clinical and metapsychological problems in the larger psychoanalytic field. (Seligman, 2018).

Some, however, have taken what I regard as a somewhat less complex view of infant-parent responsiveness and care. For example, some common 
readings of the infancy research take it to have shown that 'there is a self' in infancy, or that parental responsiveness is a matter of sympathetically reproducing the internal state of the child (paralleled in a similar view of the analyst's empathy for the patient). These conceptualizations have provided an antidote to the traditional misconception which equates infants with the id and defines their relational worlds as boundaryless and unregulated. However, they sometimes exaggerate the autonomy of the individual, perhaps misconstruing the contemporary view of the observed infant by projecting a apparently more differentiated adult subjectivity into infancy. This reading of the infancy research preserves some of the style and presuppositions of more traditional Ego Psychological and Self Psychological views of subjectivity.

Although these differences can be subtle, some of the infancy researchoriented accounts open themselves to this kind of reading. Even Daniel Stern's (1985) brilliant and still highly relevant classic Interpersonal World of the Infant relies on language that leaves it subject to this critique. (See Cushman, 1991, for example.) But finally, the infant observers present an array of concepts and descriptions which go against the idea of an autonomous self. For them, internal psychic structures are organized along affective, choreographic, kinesthetic, musical and thematic lines, rather than in terms of the specific images and other discrete representations of the person-like figures or presences.

These, then, are not memories of people per se, but rather, traces of what it felt (and feels) like to be with them. These may also take the less realistic forms associated with phantasy. The following illustrations are just a few among the infinite variety: being soothed, walking and falling, having someone turn away, being devoured, falling into bits, being damaged, enclosed by someone else, etc.

The difference between these two approaches is subtle, but substantial. Stretching the metaphor, I suggest that it would be like the difference between seeing a dance piece or hearing a string quartet in terms of the discrete parts of each individual dancer or instruments rather than hearing the interrelated fluxes of the various sounds, harmonies, rhythms, and the like. Stern's last book captures this sense of process and flux in proposing the term "forms of vitality" (Stern, 2010) to characterize essential elements of what has traditionally been called 'psychic structure'. Influenced by Stern, I have described internal objects and structures as "forms in motion". (Seligman, 2018)

As it gives internal representation a different 'look', this reading of infant development theory gives us a different self. The cohesiveness of the self becomes something of a background element, spanning the various scenarios over time and geographic and interpersonal space, but always operating in tension with the bewildering variety of experience and the 
tendency of the lived experience of interaction to transcend the impression of psychic unity. The social location of subjectivity firmly implies that self, other and the intersubjective field are inseparable and in a kind of dynamic tension, such that each of these elements is experienced in its relations with the others.' (Bromberg, 1998, has offered a related view).

The Dyadic self in Clinical Analysis: Transference, Recognition, Dissociation, Projection

Psychoanalysts who do not pay sufficient attention to the dyadic field may be prone to miss some of density and dynamism of their clinical work. In everyday analytic practice, self-cohesion often seems to dissolve into the distant background in the midst of the intensity, intimacy and depth of the analytic dialogue, especially amidst the dynamics of transference and countertransference and the emergence of unconscious mental life. Here we find one of the most essential Freudian insights: that the apparent unity of the self-Ego is a screen against an array of conflicting and incoherent processes.

Transference, especially, undercuts the picture of a cohesive 'self', since it insists on the persistence of the selves and others of the past in the apparent unity of the present. The omnipresence of projection, identification and projective identification also undercut this imaginary unity, subverting the integrity of the illusion of self-contained subjectivity in the constant processes of putting oneself in the other's place, finding the other within oneself, and the like. The growing interest in dissociation highlights the multiplicity of 'Selves' and the ways that trauma exacerbates the normal tendencies to feel like a different person in different situations. (Bromberg, 1998 , for an account of the multiplicity of 'self-states' and the ubiquity of dissociation.) Along rather different lines, Erikson's (1950/63) identity concept highlights the tensions between unity and multiplicity in the construction of subjectivity. (Seligman \& Shanok, 1996).

\section{Recognition, Mirroring and Intersubjectivity}

Since the analytic field focuses on the most profound efforts to understand and be understood, it offers special insight into the vicissitudes

\footnotetext{
${ }^{1}$ There are parallels here to other dyadically-oriented formulations, such as Kernberg's (1976) "self-other-affect units" and Bowlby's (1980) "internal working models". Stern's formulation emphasizes the choreographic dimensions to a greater extent than these, however.
} 
of recognition in the development of self-experience; that is, it discloses the extent to which feeling like a vital and integrated person depends on the attentive presence of others. This is explicit in the work of the many contemporary analysts who have called attention to the dynamics of recognition and reflection in development and psychoanalytic process, (Benjamin, Fonagy and his colleagues, and Ogden.)

It can also be seen in the work of many key analysts who have not relied on infancy research, but instead been influenced by such philosophers as Hegel (1977), Heidegger (1962) and other phenomenologists: Lacan (1949) and Laplanche (1999) are among the most prominent. Throughout his Hegelian reading of Freud, Lacan (1949) captures the fundamentally intersubjective nature of individuality, His discussion of the Mirror Stage, for example, emphasizes the extent to which being recognized by another person involves appreciating that the ideas and desires of that other are not the same as one's own. This, in turn, inevitably implies an ongoing sense of dissonance and desire, with concomitant tensions. The Lacanian mirror, unlike the Kohutian mirror (1977), is an ironic one; accurate recognition is a Sisyphean ideal: Even the best mirror provides an approximation, one from a flat, cool and twodimensional surface, rather than another living person. Narcissus' tragic misunderstanding is that he believed that unmediated reflection was reality, and so he found death where he sought love. (Hegel's (1807) analysis of the limitations and asymmetries of recognition processes offers a poignant basis for much subsequent exploration of this paradox which remains central to today's psychoanalytic explorations.).

\section{Affect Attunement and the Intersubjective self}

From this vantage point, certain problematic readings of 'attunement', especially Stern's (1985) concept of "affect attunement" can now be considered more fully. One common reading emphasizes parents' responding to children's gestures as if they were reproducing a preexisting meaning. Instead, Stern conceptualizes a transactional process through which both particular meanings and the general sense of meaningful, vital intersubjectivity are co-created, organized and established. This process is both intrapsychic and interpersonal, a dynamic process in which the infant can mean something to someone else, who in turn influences his/her experience through attending to and reacting to it: there is thus temporal and spatial dimensionality. There is a wide range of possible attuned responses, and the attuning response alters the meaning of the stimulus to which it is attuned, both in its particular meaning and its place in the infant's sense of the intersubjective world. This is the sense in which attunement is also a 
transformation. All of this applies under the special conditions of psychoanalyses as well as in everyday interactions, languages and emotions,

Thus, the concept of affect attunement offers a novel description of a fundamental form of both interpersonal interaction and psychic structure formation within which meaning and affects are signaled, communicated and (re)organized. Stern (1985) defined affect attunement as "the performance of behaviors that express the quality of feeling of a shared affect state without imitating the exact behavioral expression of the inner state." (p.142). He then went on to further distinguish between imitation and attunement:

\footnotetext{
"The reason attunement behaviors are so important as separate phenomena is that true imitation does not permit the partners to refer to the internal state. It maintains the focus of attention upon the forms of the external behaviors. Attunement behaviors, on the other hand, recast the event and shift the focus of attention to what is behind the behavior, to the quality of feeling that is being shared". (p.142)
}

\section{Illustration}

Let me illustrate this with a specific example. An infant at, let's say, sixteen months, is toddling along, enjoying the pleasure of his new motor abilities. As he accelerates in both the motor sphere and in his inner experience of excited pleasurable affect, he stumbles and falls, without physical pain and with only very mild emotional disruption, onto the soft carpet of his parents' living room. His father, who has been watching carefully and with a related, but different pleasure, says, oOOOPS! Here, the pattern of the father's vocalization corresponds - in a different communicative modality - to his son's motoric-affective contour, with its accelerating intensity coming to an abrupt halt-oOOOPS! (Note the ascending and descending size of the letters.) Such cross-modal coordination is essential in Stern's descriptions of affect attunement, reflecting the infant researchers' overall emphasis on non verbal communication and meaning-making. (Beebe, Cohen, Lachmann, \& Yothers, 2017; Tronick, 2005).

Indeed, this infant feels understood. But in what sense? Most profoundly, he is learning about the nature of understanding in the transformation of his experience into another format, in another person. This experience is intrinsically tied to his experience of the choreography of affects and interactions in the relational field, as much as to any sense of his particular 'self'. This 'self-with-other' orientation to the social context is more inclusive than one that begins with or emphasizes the individual as the locus of psychic activity.

Along these lines, Stern called careful attention to the noncategorical 
properties of affective experience. Noncategorical properties, such as rhythms, intensities and variations in intensity, are contrasted to the categorical properties, which refer to the 7 specific 'categorical' affects (disgust, anger, surprise, excitement, etc.). These noncategorical forms are not affects per se, but shapes, movement patterns, musically-organized patterns of sound and affect, interpersonal interaction patterns, and more. These are the 'stuff' of both those 'generalized representations' of interaction and, concurrently, of the self. This is at the core of an intersubjective approach to psychic structure. As I have said, Stern calls attention to the "forms of vitality" (Stern, 2010) that underlie the development of internal representations and other sorts of meanings. (Seligman, 2011).

In my example of the toddler and his father, I emphasized the formal features of a rapidly accelerating motor excitation of moving across the floor (accompanied by a sense of mastery), which then comes to an quick stop. This is an emergent bit of psychic structure, one which can take on different forms and meanings depending on the parent's reaction. To take this further, we can imagine a few different hypothetical reactions by the father. If the father gently encourages the toddler to get up and go on walking, the baby may come to feel confident that walking and falling can be lots of fun. If the father gets just a bit more alarmed and cheerfully, if slightly anxiously, diverted him into playing with his toys after the oOOOPS!, the boy might have a slightly different feeling about these kinds of rapidly accelerating but abruptly terminating excitations - that the way to handle getting excited and then interrupted is to collect yourself and find something else to do. Alternatively, if the father had become anxious and protective, the boy might have come to inhibit himself when sensing opportunities for excited exploration.

In any case, the attunement would have been a central element in a process constructing both a specific meaning-an attitude about accelerating, exploring and falling, for example - and a more generalized form of self-with-other experiencing. The variations here depend on the transformations and articulation of an experience through its recognition by another in a way which preserves some of its form and meaning at the same time that it changes them. As Stern stresses, this also involves the integrative mediation between the simultaneous senses of being similar to and different from other people in the development of "the intersubjective self" (phrase Stern's), which is sustained through such interactions throughout the life cycle. Several other related concepts can now be considered as at play in bidirectional processes of intersubjective influence, regulation and recognition: Mirroring, empathy, and projective identification. Each of these can be understood as a "form of intersubjectivity" (Seligman, 1999) organizing such dialectical and 
reciprocal relations as similarity/difference, independence/interdependence, separation/connection, and the like.

\section{'Mirroring', Empathy and the Identity/Difference 'Dialectic'}

If we assume for the moment that all of these "attunements" would have taken place in a context of generally positive affect, these episodes might well be regarded by some as episodes of 'mirroring'. As I have said, we might best think of 'mirroring', as a transaction in which the original gesture (of, say, child or patient) becomes mixed with that of the responsive other, in a generally positive affective climate. This kind of sequence continues into extended interactions, supporting the construction of new patterns of meaning and psychic structure. When things go well enough, the difference between the experiences of the person who is 'mirroring' and the one who is 'being mirrored' sustains a creative tension. When otherwise, there can be a (lesser or greater) sense of mental collapse. Overall, this is a different view from one that turns on the reproduction by the mirrorer of the internal world of the mirrored.

This approach has parallel implications for how we might think about 'empathy'. I am again stressing the sense of an interchange between two minds (or perhaps more accurately put, mind/bodies) which are finding resonance while maintaining the vitality of their difference. Empathy is a construction, rather than imitation. But some uses of this term subordinate such processes to an idealizing view of the parent or analyst 'accurately and genuinely' responding to the infant's cues. (This reading - within psychoanalysis at least — has some roots in the Kohutian Self Psychological tradition, and it is also common among many developmentally-oriented therapists, including early intervention professionals in a variety of disciplines.)

The subjective senses of being very well understood or of sharing an inner experience need not be excluded or devalued here. As Kohut reminded us, the "gleam in the parent's eye" is an essential aspect of a child's robust and buoyant life in the world. The flatness which characterizes infants whose parents do not idealize them in this usually taken-for-granted way can be quite apparent in infant-parent psychotherapy as well as in psychoanalytic work with adults (Seligman, 2016).

Nonetheless, as with 'attunement', the view of empathy as a kind of nearly identical matching can be overemphasized. This can screen out the side of parental (and clinical) responsiveness in which the differences between the infants' and parents' experiences and positions simultaneously engage both satisfactions and tensions; these can generate an array of emotions and processes, including excitement, creativity, uncertainty, fear, 
and much more. Inattention to the interplay of similarity and difference may also support therapists' idealizations, including of positive affects, of interpretive understanding, and even of the psychoanalytic method overall. In the extreme, all of this might fuel visions of near-perfect recognition envisioned as a developmental and therapeutic ideal. This can put undue pressure on both parents and analysts.

Interactive communication inevitably involves people with different histories, personalities, fantasies, bodies, varied cultural and economic situations, different positions in the life cycle and much more. Even the 'best' parents and therapists cannot avoid understanding their children's or patients' experiences through the template of their own. Notions like 'optimal frustration' or even 'correct interpretation' may lend themselves to thinking that does not adequately address the dialectic between reproduction and dissonance in recognition processes. Intersubjectivity involves two subjects. (For Self Psychological critiques of Kohut's original formulations, see, for example, discussions of "optimal responsiveness" (Bacal, 1985) or "adversarial self-objects" (Lachmann, 1986).

Commenting on a Self Psychological trope that likens empathic love to oxygen, as a universal human need, Charles Levin (2019) has written:

"... Our strong intuition about the social import of love as an obvious constituent of human well-being is not the same kind of thing as oxygen. There have been many human groups and many periods of history when nurturing attitudes toward sensitive developing young humans (let alone other adults) were not a cultural priority. Yet the species has survived. In other words, what we know as a psychological fact about human development in this case is not an actual universal in the sense of "oxygen" that we can comfortably congratulate ourselves as analysts on knowing better than others. Empathic dialogic openness to the other is a consequential but contingent variable in human affairs. ...we cannot just assume that self-psychological principles of optimal development are the answer (universal needs like oxygen) that theoretically guarantee our professional self-sufficiency as social agents. At a bare minimum, we also have to cultivate dialogical respect for differences in the social world (including our own professional group life)".

\section{Projective Identification is Bidirectional: An Intersubjective View}

The concept of projective identification captures another dimension of the complex dynamics of intersubjective fields. Most common conceptualizations still rely on the contemporary Kleinian-Bionian formulation of a unidirectional process in which the baby (or patient) induces her distress into the mother (therapist), who then 'contains' and transforms those bad feelings so as to resolve them for the moment so as to 
support progressive development (Bion, 1962). Indeed, people manage unpleasant and even intolerable feelings by casting them in relation to others' minds, as analysts know very well. But the conventional formulations seem constricted by an emphasis on the unidirectional influence of patients on their therapists, and of children on their parents. In addition, the classical Kleinian-Bionian view may be skewed by its emphasis on endogenous phantasy-based processes and motivations. (See Seligman, 1999, for a more extended development of this perspective.)

The projective identification concept will be strengthened further by stressing the bidirectionality of influence in dyadic relationships, both internal and external. An enriched application of this term would encompass the myriad ways in which parents (and analysts) influence their children's and patients' internal worlds. Infancy research offers an array of accounts of the varied pathways through which such effects take place. In addition, this reworking may well respond to many of the objections to the projective identification concept which intersubjective self psychologists such as Stolorow (Stolorow, Orange, Atwood, 1998) have posed.

\section{Illustration}

These processes can be illustrated in a brief vignette, recorded on video in an obstetrical unit just prior to the discharge of a three-day old boy. This neonate's father had been repeatedly physically abused as a child and had abused his older children, which led to their removal by the Child Protective Service. The father holds his baby up in the air just below his neck, then attempts to force him to drink water from a bottle while the baby desperately tightens his lips to show that he is satiated: the father is affected by this potential signal so as to turn it into an occasion for forcing his tyrannical inner world onto his son. The baby contracts his face in an agonizing display of discomfort, eventually going limp as his father continues overlooking these cues. Finally, the father responds to the baby's ongoing gestures by exclaiming: That's enough of your garbage!

Some who have watched this video have proposed that the father's brutal insensitivity may also include a bit of admiration; paradoxically, there seems to be some affection suffusing his pugnacity. Indeed, the father may well be identifying with both sides of the dyad of abuser and abused. Identification with the aggressor doesn't eliminate the ongoing identification with the self who was the object of the aggression; it only displaces it. This dyadic emphasis is an update of the original view of a unidirectional projection of the unbearable feeling by the projector into the recipient; rather, both sides of the problematic dyad are situated within both interactors, as well as shaping and being shaped by the intersubjective field that they are co-creating. The father's internal representations of abuse 
generated a distorting mirror which he offered to his son, as in a horrific Fun House (Bechdel, 2007).

After an extended infant-parent psychotherapy including the baby, the father and the mother/wife, the parents agreed to place this child for adoption to prevent a repetition of the earlier beatings and Child Protective removal. If we assume that the version of 'mirroring' which this man offered in the first week would continue as the baby grew, then we might well imagine that, without intervention, the boy might well become like his father - an abused/abuser with a proud, if utterly compelled conviction that this way of treating children is somehow best. Here, rather than a baby projecting his unmanageable states of mind and body into the mother, we see an bidirectional but asymmetrical pattern of influence dominated by the parent: the baby signals his distress, the father responds so as to increase it, the baby responds with a new signal, which the father then takes as a cue for further aggression, and so on.

This may be an extreme example, but it highlights the infant observers' view that influence in the infant-parent field is always bidirectional, with a variety of variations of directionality, dependence, and symmetry/ asymmetry. From the dyadically-intersubjectively oriented perspective, the same applies to psychoanalyst-analysand relationships.

\section{Clinical Applications}

Although it may seem that I have caricatured the over-emphasis on the 'unified self' and neglected the less cohesive side of subjectivity, I do believe that such views remain quite common in both theory and clinical practice. Examples could be drawn from a variety of psychoanalytic persuasions, including the general notion of 'correct' interpretation and, as I have said, the contemporary Kleinian notion of interpretation derived from 'containment' of projective identifications. I will briefly focus, however, on classical Self Psychology conceptualizations of "optimal frustration" (Wolf, 2002) and "optimal responsiveness" (Bacal, 1985). Such conceptions posit a therapist functioning as an optimally responsive selfobject, gradually becoming internalized and simultaneously fading away. There is a useful extension of developmental psychoanalysis here, but there may also be an idealization of what parents and therapists actually do, in the unavoidable connotation of the term, 'optimal'. (Intersubjective Self Psychologists have developed this critique to propose a more fully intersubjective view of both parenting and therapeutic processes.)

One unintended consequence of this may be that analysts identify with, or otherwise become tangled in, patients' understandable longings for a 
special kind of relationship which might undo the childhood nonrecognition which has been so painful and depleting. The hope that the dissonances that are part of the intersubjective field can be somehow eliminated or at least resolved can set the bar unrealistically high, such that a sense of failure ensues; this may well apply even when 'optimal responsiveness' is taken to include disappointment and disillusionment. All of this can impede the potentials for mourning and preclude the possibility of analyzing negative transferences and other fixations. Interpretation and containment may be similarly idealized by analysts of different persuasions.

Ironically, views such as these may well suffer from the same kind of retrospective fallacy which Self Psychology (along with others) has exposed in classical analysis. Freud, Klein and other seminal figures developed their models of infancy and childhood based on their analytic experience with adults or older children, rather than understanding what actually goes on between babies and their parents. Similarly, classical Self Psychology's emphasis on parents-and therapists - responding admiringly and accurately, for example, may be overdrawn as a result of its genesis in the analysis of narcissistically-fragile patients. Such patients present with characterological difficulties that require that they be appreciated in an illusory context of near-perfect understanding, to compensate for the chronic misrecognition that might has often characterized their early experience. Here, a model that emerged in response to a particular clinical situation might well lead to overly generalized inferences about childhood.

\section{Illustration}

A brief clinical vignette may further illustrate two dimensions of this point of view: first, the emphasis on the constructive and transformative aspects of recognition as opposed to the fixed reading of an already given meaning; and second, the therapeutic possibilities of dissonance in such recognition processes. In addition, I hope to call attention to how such meaning construction unrolls in an array of non-verbal affective, linguistic, choreographic and fantasmatic forms. The vignette is in most respects rather quotidian.

A particular interactive sequence occurred frequently in one phase of therapy with a young man who had been regarded as special by his parents, who were also disappointing to him in ways that precluded acknowledgement. In treatment, he would speak for relatively long periods of time in a rapid, excited way which was characterized by an apparently high degree of psychological sensitivity and sophistication, but rarely led to any real insight. During these monologues, the patient would intermittently 'wind down' and look to me for a reaction. When I would remain silent at such times 
or, alternatively, respond with interest but without complementary excitation, he would become unusually subdued and even withdrawn and angry.

As we worked to understand this situation, I began to feel that my failure to respond with greater enthusiasm to the patient's monologues was a failure to reproduce the heightened state of excitement which his overstimulating and narcissistically-invested mother had offered. She may well have been motivated in her 'attunement style' by her own wish to see her son as bright and aware of his own inside world and its productions. Thus, a particular rhythm of attunement in his childhood was reflected in a particular set of expectations about how others would respond.

This man had indeed succeeded in many of his relationships in influencing others to respond as his mother had. Detailed attention to the specific rhythms of his experience was useful in this case in sorting out the meaning of this transference interaction, especially as the patient was able to observe the meanings of the discrepancies between my responses and those which he had come to expect. For him, the experience of empathy took a particular form, one that followed the kind of attunement to which he had become accustomed as a child. Empathy had been constructed by his mother and him along particular lines, with personal meanings and in the context of distinctive configurations of self/other, affective expectations and internal object relations. My unplanned 'violation' of his expectations disequilibrated the rigid relational-affective system so as to create some new potentials, that could only emerge amidst some personal and interpersonal strain.

The therapy thus involved a deconstruction and reconstruction of his experience of being with another, a renegotiation of the terms and content of recognition. ${ }^{2}$ Such renegotiations are usually conducted in an atmosphere of at least moderate tension, since such tension is the inevitable byproduct of the dissonance between the analyst and the patient, who have different roles, needs and epistemological positions in the particular intersubjective field of the psychotherapeutic relationship. ${ }^{3}$

I believe that this kind of description is more useful in many cases than those which stress, for example, optimal frustration or responsiveness, empathy, containment of projective identifications, or 'accurate' interpretation. All the analytic persuasions run some risk of leading analysts to idealize the analytic process and sometimes, themselves in their analytic roles. Such ideals can offer useful signposts and internal support for the analyst in navigating the turbulent challenges of everyday

\footnotetext{
${ }^{2}$ See Pizer (1992) for an original conceptualization of psychoanalysis as negotiation.

${ }^{3}$ This account of the ubiquity of tension in the intersubjective field may open a door to a reconstruction of drive theory in an intersubjective context. (See Laplanche, 1999, for example.)
} 
work. But when overvalued, they can work against analytic freedom and understanding, overemphasizing the calming, reparative and/or resolution-seeking functions of therapeutic interventions at the expense of the dynamically disruptive, creative, reconstructive processes that operate in balance with them. Taking the analyst's position as a player in the hurly-burly back-and forth of dyadic mutual influence reduces these risks. Direct observation of infants and their parents supports the more complex view, as it has emphasized the creative, tranformational processes of mutual influence, mutual regulation, and the power of the infant's affective, relational and instinctive capability.

\section{REFERENCES}

Bacal, H. (1985). Optimal Responsiveness and the Therapeutic Process. In: Progress in Self Psychology, vol 1. A. Goldberg, ed. New York: Guilford.

Bechdel, A. (2007). Fun home: A family tragicomic. Houghton Mifflin Harcourt.

Beebe, B., Cohen P., Lachmann F., \& Yothers D. (2017). The mother-infant interaction picture book: Origins of attachment. New York: Norton.

Bowlby, J. (1980). Attachment and loss: Vol 3. Loss. New York: Basic Books.

Bromberg, P. (1998). Standing in the Spaces. Essays on Clinical Process Trauma \& Disassociation. Hillsdale, NJ: The Analytic Press.

Coburn, W.J. (2002). A world of systems: The role of systemic patterns of experience in the therapeutic process. Psychoanal Inq, 22,655-677.

Cushman, P. (1991). Ideology obscured: Political uses of the self in Daniel Stern's infant. Am Psychologist, 46,206-219.

Galatzer-Levy, R.M. (2002). Emergence. Psychoanalytic Inquiry, 22,798-727.

Hegel G.W.F. (1807). Hegel's phenomenology of spirit. Trans. AV Miller. Oxford: Oxford University Press.

Hegel, G.W.F. (1977). Phenomenology of spirit. Oxford: Oxford University Press.

Heidegger, M. (1962). Being and time. Oxford: Blackwell.

Kernberg, O.F. (1976). Object Relations Theory and Clinical Psychoanalysis. New York: Jason Aronson.

Kohut, H. (1977). The restoration of the self. New York: International Universities Press.

Lacan, J. (1949). The mirror stage as formative of the function of the I as revealed in psychoanalytic experience. In Ecrits: A Selection. New York: Norton.

Lachmann, F.M. (1986). Interpretation of psychic conflict and adversarial relationships: A self-psychological perspective. Psychoanalytic Psychology, 3,341.

Laplanche, J. (1999). Essays on Otherness. London and New York: Routledge.

Levin, C. (2019). On civility: Contribution to Listserve of the International Association for Psychoanalytic Self Psychology, November 5,2019.

Pizer, S. (1992). The negotiation of paradox in the analytic process. Psychoanal Dial, 2,215240.

Sander, L.W. (2002). Thinking differently: Principles of process in living systems and the specificity of being known. Psychoanal Dial, 2,11-42.

Seligman, S. (1999). Integrating Kleinian theory and intersubjective infant research: Observing projective identification. Psychoanal Dial, 9,129-159.

Seligman, S. (2005). Dynamic systems theories as a metaframework for psychoanalysis. Psychoanalytic Dialogues. J Rel Persp, 15,285-319. 
Seligman, S. (2016). Disorders of temporality and the subjective experience of time: Unresponsive objects and the vacuity of the future. Psychoanal Dial, 26,110-128.

Seligman, S. (2011). Review of Daniel Stern's Forms of Vitality: Exploring Dynamic Experience in Psychology, the Arts, Psychotherapy, and Development. J Am Psychoanal Ass, 59,859-868.

Seligman, S. (2018). Relationships in development: Infancy, intersubjectivity, and attachment. New York and London: Routledge.

Seligman, S. \& Shanok R.S. (1996). Erikson, our contemporary: His anticipation of an intersubjective perspective. Psychoanalysis and Contemporary Thought: A Quarterly of Integrative and Interdisciplinary Studies.

Stern, D.N. (1985). The interpersonal world of the infant. New York: Basic Books.

Stern, D.N. (2010). Forms of vitality: Exploring Dynamic Experience in Psychology, the Arts, Psychotherapy and Development. Oxford and New York: Oxford University Press.

Stolorow R.D. (1997). Dynamic, dyadic, intersubjective systems: An evolving paradigm for psychoanalysis. Psychoanal Psuchol, 14,337-346.

Stolorow, R.D., Orange, D.M., \& Atwood, G.E. (1998). Projective Identification Begone!: Commentary on Paper by Susan H. Sands. Psychoanal Dial, 8,719-725.

Tronick, E.Z. (2005). Why is connection with others so critical? The formation of dyadic states of consciousness and the expansion of individual states of consciousness: Coherence governed selection and the co-creation of meaning out of messy meaning making. In J. Nadel and D. Muir (Eds.), Emotional development: Recent research advances (pp. 293-316). New York: Oxford University Press.

Winnicott, D.W. (1960). The theory of the parent-infant relationship. Int J Psychoanal, 41,585 .

Wolf, E.S. (2002). Treating the self: Elements of clinical Self Psychology. New York: Guilford.

Conflict of interest: the authors declare no potential conflict of interests.

Ethics approval and consent to participate: the manuscript does not contain any elements that would allow the recognition of the patient.

Received for publication: 20 February 2020

Accepted for publication: 20 February 2020.

${ }^{C}$ Copyright: the Author(s), 2020

Licensee PAGEPress, Italy

Ricerca Psicoanalitica 2020; XXXI:211

doi: $10.4081 / r p .2020 .211$

This article is distributed under the terms of the Creative Commons Attribution Noncommercial License (by-nc 4.0) which permits any noncommercial use, distribution, and reproduction in any medium, provided the original author(s) and source are credited. 
